\title{
The Effect of Compound Herbal Remedy Used in Male Infertility on Spermatogenesis and Pregnancy Rate
}

\author{
Elaheh Ouladsahebmadarek, Giti Seyed Giasi, Arash Khaki*, Yadollah Ahmadi, Laya Farzadi, Aliyeh \\ Ghasemzadeh, Khadijeh Hajizade
}

\begin{abstract}
Objectives: TNowadays, male infertility is one of the most common issues in the medical field and the main reason for it is impaired sperm production. Assisted Reproductive Techniques (ARTs) used for treatment of infertile couples are too costly. Currently, using herbal medicine due to lower side effects and cost has gained special significance. In this study, the effect of combination of several plants was evaluated on male infertility and pregnancy rate.

Materials and Methods: In this clinical trial, 40 infertile men referring to Alzahra hospital were randomly selected to take a combination of 7 plants including Allium cepa, Zingiber officinale, Ocimum basilicum, Cinnamomum verum, Citrus sinensis' peel, Citrullus lanatus'seeds and Daucus carota' seeds in a form of $700 \mathrm{mg}$ capsule, once daily for 6 months. Before and after treatment, the patients' blood and semen samples were collected and analyzed.

Results: The number of sperms $(P=0.001)$, overall motility $(P=0.002)$, forward movement $(P=0.002)$, and normal morphology of sperms $(P=0.006)$ after treatment showed significant improvement. Also patients' blood glucose levels meaningfully reduced after treatment $(P=0.036)$. The total volume of semen, total cholesterol, testosterone, and LH levels did not significantly differ with use of the compound herbal medicine. Seven couples during the study and after six months of receiving medication got pregnant.

Conclusion: Consumption of compound herbal medicine with the lowest risk and cost, significantly improves sperm parameters. It seems that the mechanism of action is through counteracting the effects of oxidative stress.

Keywords: Herbal remedy, Male infertility, Spermatogenesis, Pregnancy
\end{abstract}

\section{Introduction}

Infertility is defined by the failure to achieve a clinical pregnancy after 12 months or more of regular unprotected sexual intercourse which involves $10 \%-15 \%$ of couples. Male factor is responsible for $40 \%$ of infertility cases. The leading cause of male infertility is impaired sperm production caused by various factors such as infections, genetic disorders, medications, aging, social and environmental factors (1-5).

Oxidative damage due to free radicals is one of the major causes of idiopathic oligospermia, even with undesirable impact on the structure of sperm produces abnormal sperm. For example, in diabetic patients by producing reactive oxygen species (ROS), free radicals of nitric oxide cause oxidative stress and thus result in testicular insufficiency through affecting spermatogenesis and estrogenic pathways (6-8). Varicocele which has been observed in $19 \%$ to $41 \%$ of infertile men is a common cause of male infertility (9-11). Increased levels of ROS and oxidative levels (oxidative stress) is one of the proposed mechanisms for impaired spermatogenesis. Vacuole formation in testis tissue is a sign of oxidative stress and is associated with aging which can be neutralized by antioxidants (1215). Lack of vitamin A, elements such as flavonoids, carnitine, folate, zinc and selenium and overall reduction of antioxidants in the diet can be one of the reasons for infertility especially oligospermia and asthenozoospermia in humans (16-18). Antioxidants like vitamin E, vitamin C, glutathione, coenzyme Q10 and natural polyphenols such as flavonoids and phenolic acids by reducing the damage caused by free radicals, strengthening blood-testis barrier and protecting and repairing sperm DNA, are effective in the treatment of male infertility (19-21).

Assisted reproductive techniques (ART) such as in vitro fertilization (IVF), zygote intra-fallopian transfer (ZIFT) and intra-cytoplasmic sperm insemination (ICSI) has solved many problems of infertility; however, due to high cost, they are not affordable by many of infertile couples. On the other hand, there are effective medications which are less expensive and available for a wide range of couples. The bioactive compounds in plant extracts are highly regarded because it is derived from natural sources and compatible with vital systems. Using herbal medicine to increase fertility and improve factors such as hormonal imbalance, oligospermia, low motility of sperm, prostatitis, varicocele, etc has been considered for a long time. Previous studies on laboratory animals indicated that plants such as Allium cepa, Zingiber officinale, Ocimum basilicum, Cinnamomum verum, Citrus sinensis' peel, Citrullus lanatus and Daucus carota' seeds as a rich source of 
vitamins, flavonoids and minerals have significant effects on oligospermia, regulation of blood testosterone levels, increased levels of superoxide dismutase (SOD) and decreased levels of malondialdehyde (MDA) (20-28). So, it is possible that a combination of above mentioned herbs can show synergistic and considerable effects than the individual components. The aim of this study was to evaluate the effects of compound herbal medicine on improving abnormal sperm analysis and male infertility.

\section{Materials and Methods}

Target population of this clinical trial study was infertile men referring to infertility clinic of Alzahra Medical Center from February 2013 to February 2014. The sample size on the basis of similar studies was calculated about $30 \mathrm{pa}-$ tients and in order to enhance the credibility of the results and possibility of loss to follow up 40 patients was considered. The inclusion criteria were men with oligospermia according to the World Health Organization (WHO) definition (sperm count below 15 million per milliliter) and lack of participation in any program for infertility treatment at least 1 year before the intervention. Patients with varicocele, those taking any medication during last 2 months and patients with abnormalities of the genitourinary system, such as cryptorchidism, testicular cancer, infection, etc were excluded from the study. Patients received a $700 \mathrm{mg}$ capsule including Allium cepa, Zingiber officinale, Ocimum basilicum, Cinnamomum verum, Citrus sinensis' peel, Citrullus lanatus and Daucus carota' seeds in equal amounts once daily for 6 months.

Samples of semen (seminal fluid) after at least 2 days to maximum 7 days of sexual abstinence (based on previous studies that indicate the best sample) before and after intervention were collected in sterile plastic containers and analyzed according to WHO criteria (semen volume, sperm count, motility, morphology and viability) in Alzahra Laboratory Center.

Fasting blood samples before inclusion and after the end of treatment were collected and blood glucose, testosterone, LH, and total cholesterol levels were analyzed.

Data including demographic information of patients, duration of infertility, side effects of herbal medicine such as nausea, vomiting, cramps and diarrhea and results of semen analysis and blood tests gathered in a questionnaire and statistically analyzed by SPSS (version 16) using paired $t$ test, Wilcoxon signed ranks test and Kolmogorov-Simonov test. Quantitative variables as mean \pm standard deviation (SD) and qualitative variables are expressed as a percentage and $P<0.05$ was considered significant.

\section{Results}

Forty infertile men with inclusion criteria enrolled in this study. The mean age of participants was $34.28 \pm 8.99$ years (range 21-60 years). The average duration of infertility was $3.25 \pm 2.04$ years (range 1-13 years). Among the participants, 3 patients $(7.5 \%)$ had a history of smoking (cigarettes) and the remaining were non-smokers. One patient (2.5\%) was excluded from the study due to loss to follow up and 39 patients (97.5\%) continued the study.

From the reported side effects of the herbal medicine according to previous studies including nausea, vomiting, cramps and diarrhea, only nausea was observed in 3 cases (7.6\%) and vomiting in 2 cases $(5.1 \%)$ which were controlled by metoclopramide tablets.

In this study, 7 couples (17.9\%) got pregnant during 6 months taking herbal medication without using ART.

The sperm parameters before and after intervention were compared using Wilcoxon signed ranks test (data did not follow a normal distribution). There was a significant improvement in sperm count, motility, forward movement and normal morphology after taking herbal medication (Table 1).

Comparison of blood glucose, cholesterol, testosterone, and LH levels before and after treatment using paired $t$ test showed significant difference between blood glucose levels ( $\mathrm{P}=0.036$; Table 2$)$.

\section{Discussion}

Fifty percent of infertility is related to male factor, especially impaired sperm production. Due to high costs of ART, using new methods especially herbal medicine plays a significant role in treatment of male infertility $(1,5)$. Several studies have shown that oxidative stress and lack of vitamins and minerals, diabetes, alcohol consumption and

Table 1. The Results of Semen Analysis Before and After Receiving Herbal Medicine

\begin{tabular}{|c|c|c|c|c|}
\hline Variable & & Before Medicine Consumption & After Medicine Consumption & $P$ value \\
\hline \multirow{2}{*}{ Semen volume $(\mathrm{mL})$} & Median & 14.64 & 15.50 & \multirow[t]{2}{*}{0.493} \\
\hline & Mean \pm SD & $2.89 \pm 2.49$ & $2.80 \pm 1.53$ & \\
\hline Sperm count $\left(10^{6} / \mathrm{mL}\right)$ & Median & 9.88 & 15.27 & 0.001 \\
\hline Total sperm count $\left(10^{6}\right)$ & Mean \pm SD & $57.62 \pm 18.19$ & $66.76 \pm 21.07$ & \\
\hline \multirow{2}{*}{ Overall motility (\%) } & Median & 8.62 & 12.71 & \multirow[t]{2}{*}{0.002} \\
\hline & Mean \pm SD & $30 \pm 34.20$ & $51.9 \pm 39.28$ & \\
\hline \multirow{2}{*}{ Forward movement (\%) } & Median & 11.56 & 17.54 & \multirow[t]{2}{*}{0.002} \\
\hline & Mean \pm SD & $18.38 \pm 10.58$ & $24.12 \pm 14.74$ & \\
\hline \multirow{2}{*}{ Normal morphology (\%) } & Median & 9.33 & 13.56 & \multirow[t]{2}{*}{0.006} \\
\hline & Mean \pm SD & $21.30 \pm 10.8$ & $24.88 \pm 10.98$ & \\
\hline
\end{tabular}


Table 2. Blood Glucose, Cholesterol, Testosterone, and LH levels Before and After Treatment

\begin{tabular}{llll}
\hline Variable & Before Medicine Consumption & After Medicine Consumption & P Value \\
\hline Fast blood sugar $(\mathrm{mg} / \mathrm{dL})$ & $89.65 \pm 11.65$ & $86.21 \pm 11.08$ & 0.036 \\
Cholesterol $(\mathrm{mg} / \mathrm{dL})$ & $165.12 \pm 47.91$ & $157.91 \pm 42.81$ & 0.176 \\
Testosterone $(\mathrm{ng} / \mathrm{dL})$ & $4.41 \pm 2.26$ & $4.59 \pm 2.00$ & 0.515 \\
LH ( IU/L) & $5.13 \pm 2.08$ & $5.13 \pm 1.78$ & 0.19 \\
\hline
\end{tabular}

smoking are major causes of impairment in quality and quantity of sperm production (29). Although there are numerous studies conducted on animal models to investigate the therapeutic effects of herbal medicine, there are a few on human.

Khaki et al investigated the effects of Basil on spermatogenesis in rats and showed that total sperm count has been improved (23). Kanaze et al in a research on Citrus reported improvement in total motility of sperms and also increase in total antioxidant capacity (TAC) and SOD and decrease in MDA levels (25).

Khaki et al investigated onion's effect on spermatogenesis in rats infected by the Toxoplasma gondii, and indicated that the fresh extract of onion had potent antioxidant effect and improved all parameters of sperm like, quantity, motility and vitality (21). Onion has been known as a rich source of quercetin with strong antioxidant effects, positive impact on spermatogenesis and testosterone level (30-32). Another study has confirmed significant effect of quercetin on sperm motility (33).

Moretti et al studied the antioxidant effects of flavonoids and showed their positive results on spermatogenesis. The research on flavonoid's subcategory, such as luteolin, catechin, fiestin, Moretti et al emphasized that their role in improving spermatogenesis mostly was dependent on their antioxidant effect (34). Likewise, Zingiber, Cinnamon, Citrullus lanatus and Daucus carota' seeds had significant effects on oligospermia, regulation of blood testosterone levels, increased levels of SOD and decreased levels of MDA.

We chose a combination of above mentioned herbs rich in vitamins, flavonoids, minerals, and quercetin with potent antioxidant effects for treatment of men with impaired spermatogenesis and the results were consistent with or even better than previous studies on sole components. Because of using a minimum dose of herbs, the least side effects were reported and medication was highly tolerated. Another important outcome was $17.9 \%$ spontaneous pregnancy rate (7 cases) which occurred during 6 months after starting the medication.

\section{Conclusion}

This combination of herbs has minimal side effects and easier to handle than previous studies. It is associated with high satisfaction due to herbal structure of medicine, treatment cost and low complications. According to our results, it seems that the herbal combination improves sperm parameters and affects the treatment of male infertility. So, it is recommended that before selecting ART, compound herbal medicine to be tried as a safe and appropriate alternative.

\section{Ethical Issues}

The research proposal has been approved by Women's Reproductive Health Research Center, Tabriz University of Medical Sciences and received IRCT code from Iranian Registry of Clinical Trials (IRCT2012071410278N1; http://en.search.irct.ir/view/10255).

\section{Conflict of Interests}

The authors declare no conflict of interests.

\section{Financial Support}

The research proposal has been financially supported by Women's Reproductive Health Research Center, Tabriz University of Medical Sciences.

\section{Acknowledgments}

We acknowledge the sincere cooperation of Infertility Department at Alzahra hospital. This study has been done as a thesis for specialty degree of Giti Seyed Giasi in Women's Reproductive Health Research Center, Tabriz University of Medical Sciences.

\section{References}

1. Rowe PJ, Comhaire FH, Hargreave TB, Mahmoud Ahmed MA. WHO manual for the standardized investigation, diagnosis and management of the infertile male. Cambridge: Cambridge University Press; 2000:37.

2. Cooper TG, Noonan E, von Eckardstein S, et al. Hum Reprod Update. 2010;16(3):231-45. doi: 10.1093/ humupd/dmp048.

3. World Health Organization. World Health Organization Laboratory Manual for Examination of Human Semen. Cambridge: Cambridge University Press; 1999.

4. Sarvari A, Naderi MM, Heidari M, Zarnani AH, JeddiTehrani M. Effect of environmental risk factors on human fertility. J Reprod Infertil 2010;11(4):211-26.

5. Schulte RT, Ohl DA, Sigman M, Smith GD. Sperm DNA damage in male infertility: etiologies, assays, and outcomes. J Assist Reprod Genet. 2010;27(1):3-12.

6. Amiri I, Karimi J, Piri H, et al. Association between nitric oxide and 8-hydroxydeoxyguanosine levels in semen of diabetic men. Syst Biol Reprod Med. 2011;57(6):292-5. doi: 10.3109/19396368.2011.621508.

7. Benitez A, Perez Diaz J. Effect of streptozotocindiabetes and insulin treatment on regulation of Leydig cell function in the rat. Horm Metab Res. 1985;17:5-7.

8. Chandel A, Dhindsa S, Topiwala S, Chaudhuri A, Dandona P. Testosterone concentration in young patients with diabetes. Diabetes Care 2008;31(10):13-7. doi: $10.2337 / \mathrm{dc} 08-0851$. 
9. Coskun O, Kanter M, Korkmaz A, Oter S. Quercetin, a flavonoid antioxidant, prevents and protects streptozotocin-induced oxidative stress and beta-cell damage in rat pancreas. Pharmacol Res. 2005;51(2):117723.

10. Enciso M, Muriel L, Fernández JL, et al. Infertile men with varicocele show a high relative proportion of sperm cells with intense nuclear damage level, evidenced by the sperm chromatin dispersion test. J Androl. 2006;27(1):106-11.

11. Greenberg SH. Varicocele and male infertility. Fertile Steril. 1997;28(7):699-706.

12. Marmar JL. The pathophysiology of varicoceles in the light of current molecular and genetic information. Hum Reprod Update. 2001;7(5):461-72.

13. Zini A, de Lamirande E, Gagnon C. Reactive oxygen species in semen of infertile patients: levels of superoxide dismutase and catalase-like activities in seminal plasma and spermatozoa. Int J Androl. 1993;16(3):183-8.

14. Jervis KM, Robaire B. The effects of long-term vitamin E treatment on gene expression and oxidative stress damage in the aging brown Norway rat epididymis. Biol Reprod. 2004;71(4):1088-95.

15. Olson GE, Winfrey VP, Hill KE, Burk RF. Sequential development of flagellar defects in spermatids and epididymal spermatozoa of selenium-deficient rats. Reproduction. 2004;127(3):335-42.

16. Agarwal A, Prabakaran SA, Said TM. Prevention of oxidative stress injury to sperm. J Androl. 2005;26(6):654-60.

17. Pryce JE, Royal MD, Garnsworthy PC, Mao IL. Fertility in the high-producing dairy cows. Livest Prod Sci. 2004;86(1-3):125-35.

18. Mendiola J, Torres-Cantero AM, Vioque J, et al. Low intake of antioxidant nutrients is associated with poor semen quality in patients attending fertility clinics. Fertil Steril. 2010;93(4):1128-33. doi: 10.1016/j. fertnstert.2008.10.075.

19. Koskimies AI, Savander M, Ann-Marie N, Kurunmäki H. Sperm DNA damage and male infertility (in Finnish). Duodecim. 2010;126(24):2837-42.

20. Khaki A, Fathiazad F, Nouri M Khaki AA, Ozanci C. The effects of ginger on spermatogenesis and sperm parameters of rat. Iran J Reprod Med. 2009;7(1):7-12.

21. Khaki A, Fathiazad F, Nouri M, Khaki AA, Khamenehi HJ, Hamadeh M. Evaluation of androgenic activity of allium cepa on spermatogenesis in rat. Folia Morphol. 2009;68(1):45-51.

22. Khaki A, Fathiazad F, Nouri M, Khaki A, Maleki NA, Khamnei HJ, et al. Beneficial effects of quercetin on sperm parameters in streptozotocin -induced diabetic male rats. Phytother Res. 2010;24(9):1285-91. doi: 10.1002/ptr.3100.

23. Khaki A, Fathiazad F, Nouri M, Khaki AA. Effects of basil, Ocimum basilicum on spermatogenesis in rats. J Med Plants Res. 2011;5(18):4601-4.

24. Azab KSh, Mostafa AH, Ali EM, Abdel-Aziz MA. Cinnamon extract ameliorates ionizing radiationinduced cellular injury in rats. Ecotoxicol Environ Saf. 2011;74(8):2324-9. doi: 10.1016/j.ecoenv.2011.06.016.

25. Kanaze FI, Termentzi A, Gabrieli C, Niopas I, Georgarakis M, Kokkalou E. The phytochemical analysis and antioxidant activity assessment of orange peel (Citrus sinensis) cultivated in Greece-Crete indicates a new commercial source of hesperidin. Biomed Chromatogr. 2009;23(3):239-49. doi: 10.1002/ bmc.1090.

26. Alasalvar C, Grigor JM, Zhang D, Quantick PC, Shahidi F. Comparison of volatiles, phenolics, sugars, antioxidant vitamins, and sensory quality of different colored carrot varieties. J Agric Food Chem. 2001;49(3):1410-6.

27. Prakash O, Bhushan G. A study of inhibition of urease from seeds of the water melon (Citrullus vulgaris). J Enzyme Inhib. 1998;13(1):69-77.

28. Rimando AM, Perkins-Veazie PM. Determination of citrulline in watermelon rind. J Chromatogr A. 2005;1078(1-2):196-200.

29. Zhang Q, Xiao Y, Zhuang W, et al. Effects of biovar I and biovar II of Ureaplasma urealyticum on sperm parameters, lipid peroxidation, and deoxyribonucleic acid damage in male infertility. Urology. 2014;84(1):8792. doi: 10.1016/j.urology.2014.04.014.

30. Silva EC, Cajueiro JF, Silva SV, Soares PC, Guerra MM. Effect of antioxidants resveratrol and quercetin on in vitro evaluation of frozen ram sperm. Theriogenology. 2012;77(8):1722-6. doi: 10.1016/j. theriogenology.2011.11.023.

31. Carrell DT, Zobell RL, Middleton RG, Urry RL. A functional analysis and the potential clinical significance of 7 categories of sperm morphology. J Urol. 1994;151(2):376-80.

32. Harwood M, Danielewska-Nikiel B, Borzelleca JF, Flamm GW, Williams GM, Lines TC. A critical review of the data related to the safety of quercetin and lack of evidence of in vivo toxicity, including lack of genotoxic/carcinogenic properties. Food Chem Toxicol. 2007;45(11):2179-205.

33. Gibb Z, Butler TJ, Morris LH, Maxwell WM, Grupen CG. Quercetin improves the postthaw characteristics of cryopreserved sex-sorted and nonsorted stallion sperm. Theriogenology. 2013 1;79(6):1001-9. doi: 10.1016/j.theriogenology.2012.06.032.

34. Moretti E, Mazzi L, Terzuoli G, et al. Effect of quercetin, rutin, naringenin and epicatechin on lipid peroxidation induced in human sperm. Reprod Toxicol. 2012;34(4):651-7. doi: 10.1016/j.reprotox.2012.10.002.

Copyright (c) 2016 The Author(s); This is an open-access article distributed under the terms of the Creative Commons Attribution License (http://creativecommons.org/licenses/by/4.0), which permits unrestricted use, distribution, and reproduction in any medium, provided the original work is properly cited. 